\title{
Layout and Performance of the Power Electronic Converter Platform for the VSYNC Project
}

\author{
Tom Loix, Student Member, IEEE, Sven De Breucker, Student Member, IEEE, \\ Piet Vanassche, Member, IEEE, Jeroen Van den Keybus, Member, IEEE, Johan Driesen, Member, IEEE, \\ and Klaas Visscher Member, IEEE,
}

\begin{abstract}
This paper presents the power electronic platform used for the VSYNC project. In this project, inverters are controlled in such a way as to exhibit a virtual rotational inertia towards the grid, in order to limit grid frequency variations in grids containing a high share of inverter-connected DER. First the layout and operation of the platform are described in detail, showing its versatility for research purposes. Next the performance of the platform is illustrated using experimental results obtaining using a grid-connected inverter in a laboratory setup.
\end{abstract}

Index Terms-Virtual synchronous generator, power electronic converter, rapid prototyping platform, grid-connected inverter, virtual rotational inertia.

\section{INTRODUCTION}

$\mathbf{T}$ HIS paper presents the layout, operation principle and performance of the power electronic converter platform designed for use in the VSYNC project [1]. The aim of this project is to enable distributed energy resources (DER) connected to the grid through an inverter to exhibit a virtual rotational inertia towards the grid. The reason for this is that in the future a significant part of the grid-connected energy sources, which at present are mostly synchronous generators, might be inverter-connected. While synchronous generators have a certain amount of rotational inertia, limiting and damping grid frequency variations in case of an imbalance between power generation and demand, power electronic converter do not inherently have such inertia. As the use of an inverter allows flexible control of the power exchanged with the grid as well as of the waveforms of the voltage and current, it is possible to adapt the inverter control in such a way as to emulate the behavior of a synchronous generator with a certain amount of inertia. In order to do this, some energy storage must be connected to the inverter (either directly to the DC-link, through a DC-DC converter or through a rectifier). The control scheme determines the exchange of active and reactive power between the inverter and the grid, allowing to emulate the behavior of a synchronous machine with (possible adaptive) rotational inertia. An inverter with energy storage

T. Loix, S. De Breucker and J. Driesen are with the Division of Electrical Energy and Computer Architectures, Department of Electrical Engineering, KU Leuven, Kasteelpark Arenberg 10, 3001 Heverlee, Belgium, e-mail: tom.loix@esat.kuleuven.be.

P. Vanassche and J. Van den Keybus are with Triphase, Romeinse straat 18, 3001 Heverlee, Belgium.

K. Visscher is with the Energy Research Center of the Netherlands (ECN), group Power System and Information Technology, 1755 ZG Petten, the Netherlands. being controlled in this manner is called a virtual synchronous generator (VSG) [2].

In the VSYNC project, inverter control schemes are first proposed and tested using simulations before their performance is verified on a laboratory setup. The final step in the project is to test VSG operation in the field. Two field tests will be organized: one in the Netherlands with 10 VSG units each having an active output power of $5 \mathrm{~kW}$ and one in Romania with one $100 \mathrm{~kW}$ VSG unit.

This paper starts with a detailed description of the layout and operation of the Triphase rapid prototyping platform used for the laboratory experiments and the field tests in the Netherlands during the VSYNC project. It is shown that this platform allows the user to quickly develop and test various inverter control schemes without requiring extensive knowledge of power electronics as well as its versatility for research purposes. Next, the performance of the platform is illustrated using experimental results obtained in a laboratory setup with a grid-connected inverter. Finally, some concluding remarks and future work are given.

\section{LAyout ANd Operation of The Power EleCtronic CONVERTER PlatForm}

The power electronic converter platform which will be used to implement and test this control algorithm is produced by the Belgian company Triphase [3], a spin-off of the KU Leuven Electrical Engineering Department. It allows the use of a control scheme designed in Matlab Simulink, with easy access to the available measurements and the possibility to change some control parameters online. The platform is built in a cabinet, including two three-phase DC-AC inverters; each containing three half bridges which can be controlled independently, and all necessary filter passives and protection devices. This layout allows implementing a three-phase fourwire inverter grid interface (using an LC output filter and an output transformer) as well as three DC-DC converters in a single cabinet and controlled through a single Simulink model. More details on this rapid prototyping power electronic platform can be found in [4] and [5].

\section{A. Layout}

Figure 1 shows a schematic overview of the converter cabinet topology. It contains two three-phase inverters, each having three half bridges equipped with IGBT modules and sharing a common DC link. In order to form a three- phase four-wire 


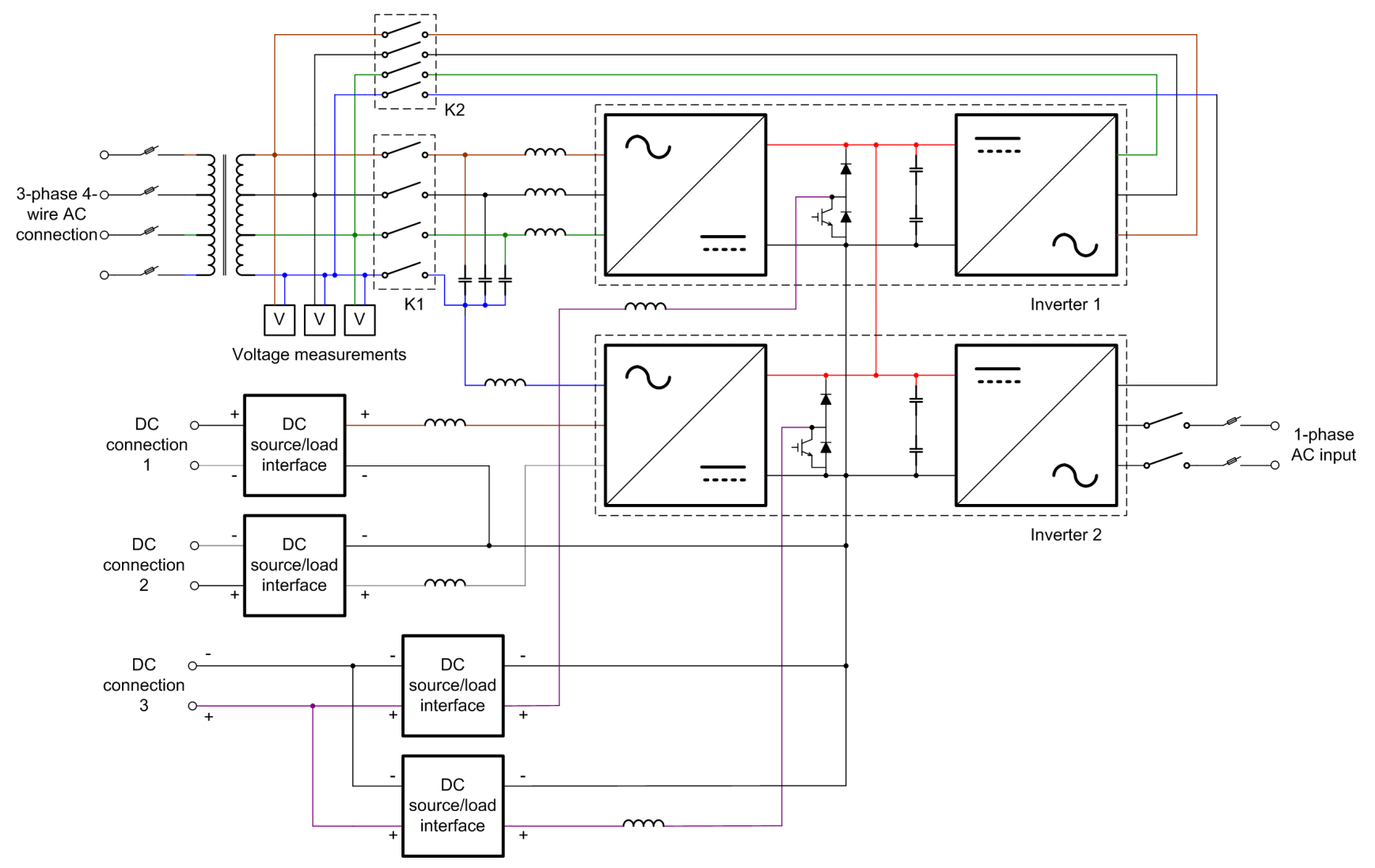

Fig. 1. Layout of the VSYNC power electronic platform

AC grid-connected interface with an actively controlled neutral conductor, all three half bridges of the first inverter as well as one half bridge of the second inverter are used.

The inverter output is connected to the grid using an LCL output filter, including an output transformer, the leakage inductance of which serves as the secondary filter inductance. The output filter is not only a differential mode filter; it also includes common mode filter components. First the output transformer presents a large impedance to the common-mode currents possibly flowing towards the grid, as the only path for these currents uses the parasitic capacitance between the primary and secondary transformer winding. Second a common mode choke is added directly at the inverter output. The third and final measure against common mode current flow into the grid is a feedback path between the LCL filter capacitor's star point and the inverter DC link, formed by a parallel connection of a capacitor and the series connection of a capacitor and a resistor. This filter component presents a low impedance path for common mode currents back to its source (which is the inverter DC link).

The cabinet also contains three DC interfaces. The first two DC interfaces use the two remaining half bridges of the second inverter and allow bidirectional energy flow, making it suitable for connecting energy storage. The third DC interface uses the IGBTs of the DC link break chopper of both inverter units. As each break chopper contains one IGBT, this DC interface only allows unidirectional energy flow, making it suitable for connecting either DC loads or sources to the inverter's DC link. DC inductors are included in the cabinet, allowing some basic DC-DC converter topologies to be implemented. The inverter's DC link can be precharged using the diode rectifier bridge present in each module, either using the single-phase or the three-phase AC input. For the latter, the contactor K2 must be closed. Contactor $\mathrm{K} 1$ can be used to connect the inverter output to the grid. Both contactors can be controlled from the Matlab command window.

The available measurements include the inverter output currents, the DC link voltage and the grid voltages. Additional measurements can be installed, such as the grid currents or the filter capacitor voltages.

\section{B. Operation}

The system uses two PCs: the Engineering PC and the Target PC. The Target PC is a Linux server who interacts with the inverters, passes on commands from the user and gathers data requested by the user, like current and voltage measurements. The cabinet includes an EtherCAT fieldbus system, allowing Ethernet communication with the Target PC. The Engineering PC is the computer on which the user runs the Simulink model, changes certain reference values and displays measurement results.

First, a Simulink control scheme is made, containing specially designed blocks for interacting with the inverter cabinet. Next, this model is built into $\mathrm{C}$ code and uploaded to the Target PC. Then, the model is started on the Target PC and the 
Engineering PC connects to the Target PC, allowing the user to control the inverter behavior using the Simulink model.

\section{CONTROL OF THE PLATFORM}

The main goal of the VSYNC project is to show that gridcoupled inverters with a certain amount of energy storage connected to their DC link are able to stabilize the grid frequency in case of unbalances between the generated and consumed power. This is achieved by emulating a virtual rotating inertia for each inverter, analogous to the inertia of a synchronous generator. Virtual inertia emulation requires the inverter to be able to store or release an amount of energy depending on the grid frequency's deviation from its nominal value, as happens with a grid-connected synchronous generator.

The control algorithm for the VSG can be split into three parts, each of which will be described below:

- High-level grid-connected inverter control, calculating the active and reactive power to be exchanged between the inverter and the grid in order to achieve the control goal, e.g. stabilizing the grid frequency.

- Low-level grid-connected inverter control, determining the inverter output voltage to be applied in order to achieve the active and reactive power exchange between the inverter, the energy storage units and the grid as demanded by the high-level control.

- Control of the DC-DC converters interfacing the energy storage units to the inverter's DC link.

\section{A. High-level control - virtual inertia emulation}

The goal of the high-level control of the VSG is to emulate an energy source with rotational inertia. The kinetic energy stored in the rotor of a synchronous generator, having a moment of inertia $J\left[\mathrm{~kg} / \mathrm{m}^{2}\right]$ and rotating at $\omega_{m} \mathrm{rad} / \mathrm{s}$, is given by equation (1).

$$
E_{k i n}=\frac{J \cdot \omega_{m}^{2}}{2}
$$

In case of an unbalance between the generated and consumed power in the grid, the kinetic energy stored in the rotating mass of a generator is used to compensate for this deviation. As the grid frequency is determined by the speed of the synchronous generator, this results in a frequency deviation from its nominal value.

In order to program this behavior into the control of the grid-coupled inverter, one must determine the amount of active and reactive power the inverter needs to exchange with the grid as a function of the grid frequency. The amount of power that the inverter can use to compensate for a frequency deviation also depends on the type of energy source present in the VSG. In case of distributed generator, possibly converting some form of renewable energy to electricity, the main purpose of the inverter will be to deliver active power to the grid, leaving only a limited amount of inverter power for compensation of frequency deviations (virtual inertia emulation). Depending on the nature of the primary energy

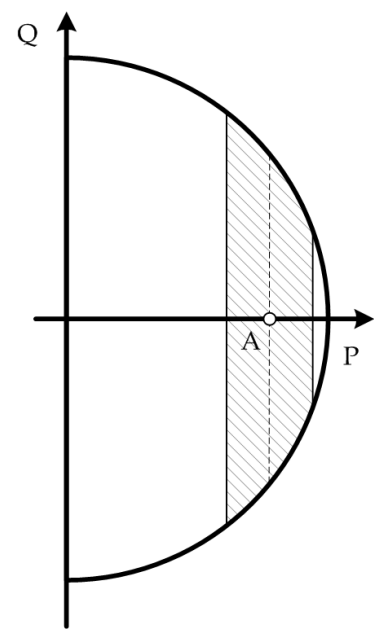

Fig. 2. VSG operating area in the presence of a DG unit delivering active power A to the grid

source, some part of the energy storage capacity will be used to provide a more or less constant active power to the grid, and the remaining part can be used to emulate rotational inertia. VSG operation will be restricted to a small area around the active power setpoint determined by the energy source's active power delivery to the grid as well as the inverter current rating. This is illustrated in Figure 2, where A is the active power delivered to the grid and the shaded area represents the operating area of the VSG. In case the inverter is used to interface an energy source as well as a large energy storage unit to the grid, whose main objective are to stabilize the grid frequency, the full inverter power rating can be used for virtual inertia emulation. Referring to the operating area in Figure 2, the full circle in the PQ-domain can be used by the VSG (also negative active power exchange). The state of charge of the energy storage units connected to the inverter's DC link can also prohibit certain operating conditions, e.g. when a battery is fully charged, no more active power can be drawn from the grid.

The active power balance for a system containing several rotating machines can be expressed by equation (2). Here, $P_{m, i}$ is the mechanical power for machine $i, P_{e, i}$ is the electric power delivered or drawn by machine $i, p_{i}$ is the number of pole pairs for machine $i$ and $\omega_{\text {grid }}$ is the grid pulsation $[\mathrm{rad} / \mathrm{s}]$.

$$
\frac{d\left(\sum_{i} \frac{J_{i} \cdot \omega_{m, i}^{2}}{2}\right)}{d t}=\sum_{i} P_{m, i}-P_{e, i}=\sum_{i} \frac{J_{i}}{p_{i}^{2}} \cdot \omega_{\text {grid }} \cdot \frac{d \omega_{\text {grid }}}{d t}
$$

Virtual rotational inertia emulation can be achieved by controlling the inverter to exchange active power $P_{V S G}$ with the grid (equation (3)). In this equation, $J_{V S G}$ represents the virtual moment of inertia of the VSG and $p$ is a constant determining the amount of compensating power delivered to or drawn from the grid in response to a grid frequency variation.

$$
P_{V S G}=-p \cdot J_{V S G} \cdot \omega_{\text {grid }} \cdot \frac{d \omega_{\text {grid }}}{d t}
$$




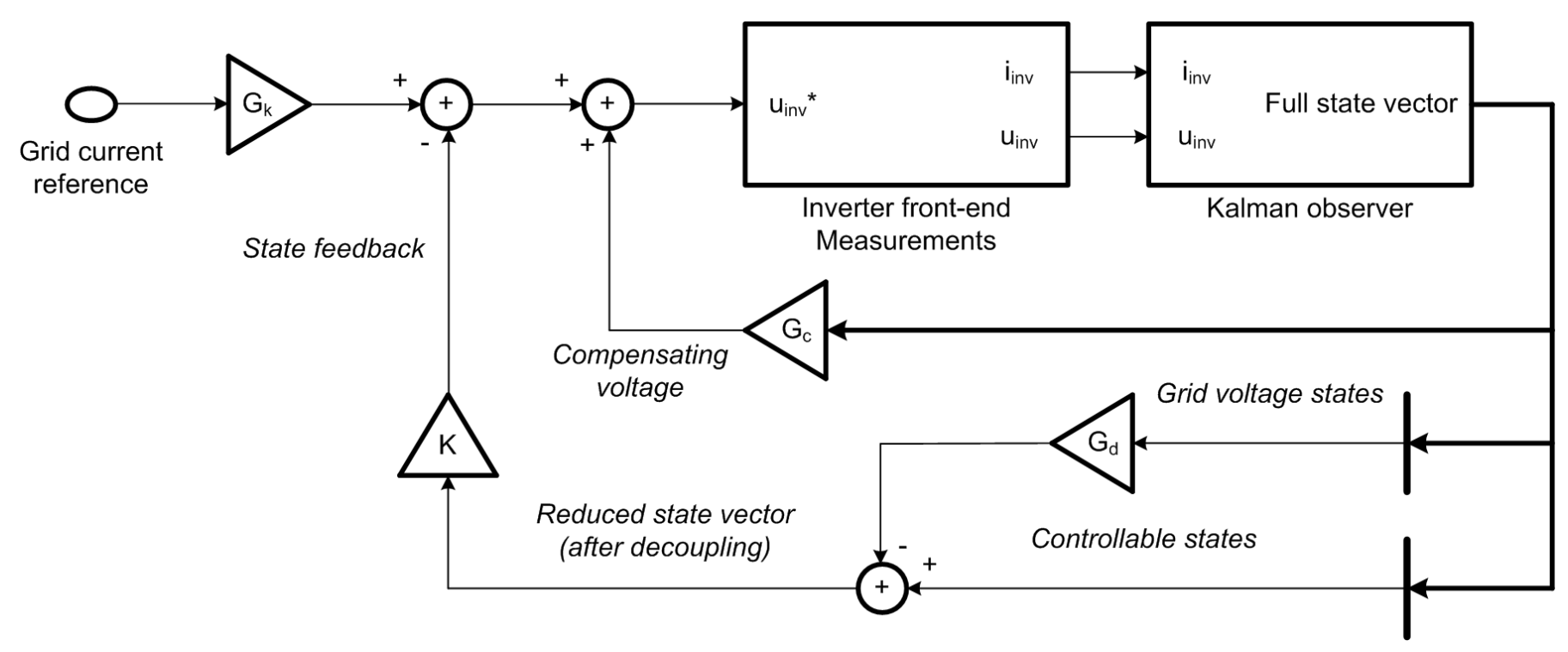

Fig. 3. Overview of the low-level grid-coupled inverter control scheme

The high-level control scheme can be extended with some more functions, e.g. droop control for primary voltage and frequency control [6]-[7].

\section{B. Basic low-level control of the grid-connected inverter}

The output of the high-level control is generally a reference for the active and reactive power or current to be exchanged between the inverter and the grid. The purpose of the low-level control is to calculate the inverter output voltage to be applied in order to realize the desired power exchange. The proposed low-level control scheme is based on [8]-[9] and is briefly described below. Figure 3 illustrates the basic components of the low-level control scheme.

The low-level control scheme uses a Linear Quadratic Gaussian (LQG) controller to regulate the power exchange between inverter and grid. The inputs for the control scheme are the reference values for the active and reactive current, usually given in the Park domain. These reference values are transformed back to the time domain and used as control input.

The model used to design the LQG controller contains the following elements:

- A model of the LCL filter: the state variables are the inverter output current, the voltage across the filter capacitors and the filter output current (towards the grid). The inverter voltage and the grid voltage are inputs to this model.

- A one sample period delay for the inverter voltage: the inverter voltage reference calculated during a certain sample period is applied during the next sample period.

- An oscillator model for estimating the grid voltage: here, the fundamental voltage as well as the fifth and seventh harmonics are estimated.

As the inverter voltage and the grid voltage are two independent input signals for the LCL filter, a model is built for each of them. Then, using the superposistion principle, both models are combined into one large model, describing the influence of both voltages on the filter state variables.

Next, the Kalman observer and state feedback gain are designed. The known inputs to the Kalman observer, which are used for the estimation of the model's state variables are the inverter output current (which is measured for the inverter protection) and the inverter output voltage reference. This way, the number of sensors needed is kept low while enabling fast and accurate state estimation. For the design of the state feedback gain ( $\mathrm{K}$ in Figure 3), it is important to note that some model states are uncontrollable: the states used for the estimation of the grid voltage harmonic components. Thus all uncontrollable states are omitted and a reduced state vector is constructed. The LQG cost function puts major stress on good control of the grid current.

In order to achieve good performance using state feedback, the effect of the grid voltage on the controllable states should be eliminated. This can be achieved by feeding a compensating voltage to the inverter output voltage reference. The compensating voltage is calculated by multiplying the full state vector by the gain $G_{c}$ [8]. However, this approach only allows to erase the effect of the grid voltage on one controllable state. As the control scheme aims to control the current exchanged with the grid, the compensating voltage is calculated such that the grid current is free of disturbance. Next, the effect of the grid voltage and the compensating voltage on the remaining controllable states must be eliminated. This is accomplished by calculating the disturbance effect for each state (using the gain $G_{d}$ ) and subtracting it from the state value before feeding it to the state feedback gain.

The grid current reference is multiplied by $G_{k}$, which is in fact the transfer function between the inverter output voltage and the grid current. The inverter output voltage reference must be converted to a duty cycle reference for each of the inverter half bridges. An FPGA in the inverter platform converts the duty cycle references in PWM control signals for the IGBT's. Before sending the duty cycle reference to the FPGA, the 


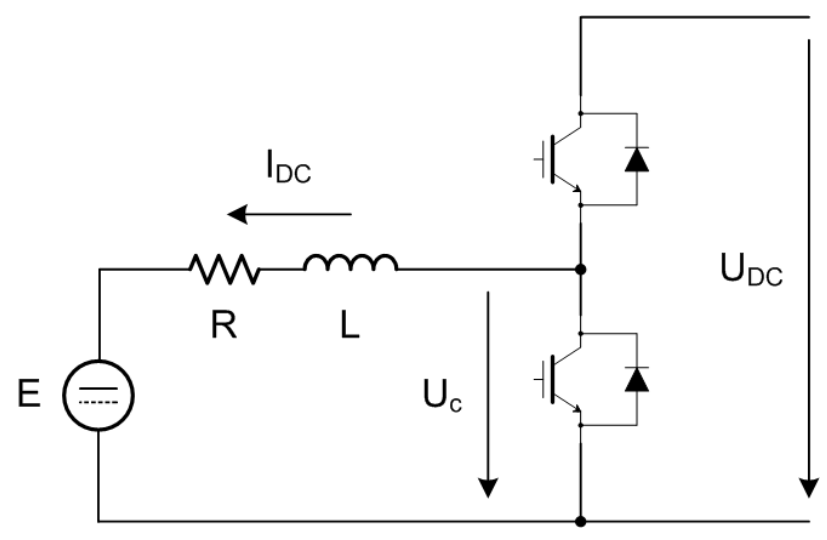

Fig. 4. Setup for a bidirectional buck converter

inverter switches' dead-time is estimated and compensated for.

\section{Control of the DC-DC converters}

As mentioned above, the inverter cabinet contains three DC-DC interfaces, two of which allow bidirectional power exchange and the other one allowing only unidirectional power flow. The inverter cabinet hardware enables the use of buck converters in order to exchange power between the DC energy source (energy storage, generator or load) and the inverter DC link. A simple control scheme is used for the buck converter, as described below. More complex control schemes can be used well, as long as the available measurements are sufficient and the total model complexity (including the grid-coupled inverter control scheme, which is run on the same Target PC) does not become to large, given the model sample period and the Target PC's computational abilities.

Figure 4 shows the setup for a bidirectional buck converter, including the most important control variables and parameters. The output voltage to be applied by the inverter half bridge is calculated by equation (4).

$$
U_{c, r e f}=\frac{R \cdot L}{T_{c l}} \cdot\left(I_{D C, r e f}-I_{D C}\right)+R \cdot I_{D C, r e f}+E
$$

The available measurements are the half bridge output current and the inverter DC link voltage. The back-EMF E is estimated by an observer. The calculated half bridge output voltage has to be converted to a duty cycle reference, from which the inverter platform generates the necessary PWM control signals for the IGBT's. For this conversion, dead-time compensation is added, resulting in better control performance.

\section{EXPERIMENTAL RESULTS}

In order to illustrate the performance of the control schemes described above, several laboratory experiments are done. During the first test, no energy source is connected to the DC-DC converters and the grid-coupled inverter is used to control the inverter DC link voltage (with a $5 \mathrm{~ms}$ closedloop time constant) and the reactive power exchange with the grid. Experimental results are shown in Figure 5. At startup, the DC link voltage is regulated to $650 \mathrm{~V}$ and the
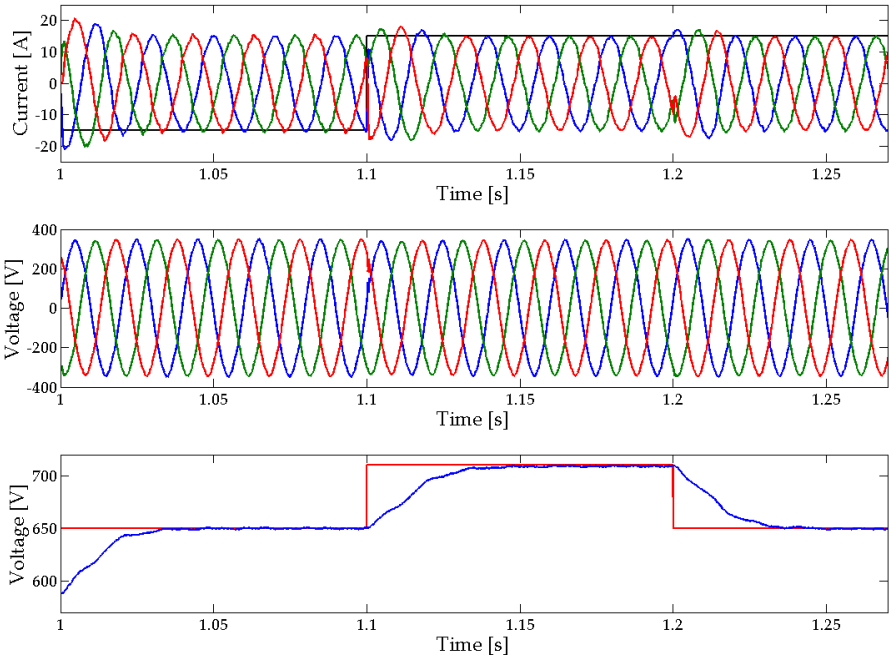

Fig. 5. Experiment with simultaneous steps in DC link voltage and reactive power exchange with the grid

reactive current magnitude reference is $-15 \mathrm{~A}$ (meaning the inverter behaves as a capacitor towards the grid). The black line in the upper graph (showing the inverter current) is the current reference magnitude. The middle graph shows the grid voltage, while the lower graph depicts the DC link voltage (blue) and its reference (red). One can see that the current magnitude is slightly larger during the DC link charging but becomes purely reactive after the DC link voltage has reached its setpoint. At time $t=1.1 \mathrm{~s}$, the DC link voltage reference is increased to $710 \mathrm{~V}$ and, at the same time, the reactive current magnitude reference is changed from $-15 \mathrm{~A}$ to $15 \mathrm{~A}$. These simultaneous changes in setpoints result in a slightly higher current (with both active and reactive component) during DCbus charging. The current reference change towards inductive behavior results in a very short settling time with minor transient disturbance on the inverter current. Lowering the DCbus voltage to $650 \mathrm{~V}$ at $\mathrm{t}=1.2 \mathrm{~s}$ again slightly disturbes the inverter current waveform, as some active power must be sent back to the grid.

The second test illustrates the performance of the DC-DC converters. A DC generator with controllable output voltage is connected to the low-voltage side of a bidirectional Buck converter. This setup allows bidirectional flow of energy between the inverter's DC link and the generator. Figure 6 shows the results of the experiment. The upper graph depicts the current through the DC-DC converter (blue) and its reference value (red). The lower graph shows the DC link voltage (blue), as well as the reference voltage (red). The grid-coupled inverter controls the DC link voltage at $650 \mathrm{~V}$ without exchanging any reactive power with the grid. The DC-DC converter control starts at $t=1 \mathrm{~s}$. Note that a reference of $-14 \mathrm{~A}$ (power flow from the generator towards the inverter DC link) is applied at $\mathrm{t}=0 \mathrm{~s}$. The rate of change of the DC current reference is limited to $10 \mathrm{~A} / \mathrm{s}$. It can be seen that the DC-DC converter is able to control its current to the desired value. Note that the DC link voltage slightly deviates from its reference value. Additional power is added to the DC link through the DC-DC 

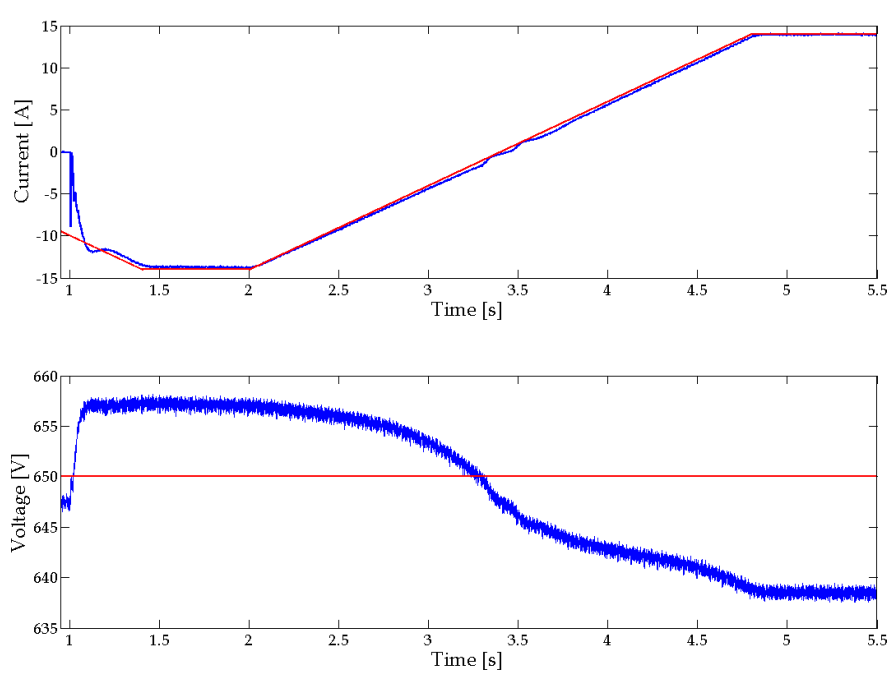

Fig. 6. Experiment with change in DC-DC converter current reference DC-DC converter current and inverter DC link voltage

converter, resulting in an increase of the voltage. This can be explained by the fact that the power exchange with the DCDC converters is only fed to the DC link voltage controller as a feedforward term. In case more strict DC link voltage control is required, this control loop can be adapted by adding some feedback for coping with the power exchange between the DC link and the DC-DC converters. At $t=2 \mathrm{~s}$, the current reference is changed to $14 \mathrm{~A}$. The control scheme is able to track the reference change well, without any overshoot. As power is drawn from the DC link towards the DC generator, the DC link voltage drops slightly below its reference value. An alternative control implementation might use one or several DC-DC converters to control the DC link voltage, enabling the grid-coupled inverter to control both the active and reactive power exchange with the grid.

Figure 7 gives a more detailed view of the grid-coupled inverter output currents (upper graph) and the grid voltage (lower graph) during the second experiment. At the time of this snapshot, the DC-DC converter draws 14 A from the inverter's DC link, with a generator voltage of $141 \mathrm{~V}$. This means an active power exchange of $1974 \mathrm{~W}$ occurs between the inverter and the generator. The active power is drawn from the grid, which results in an inverter phase current of 2.86 $\mathrm{A}_{\mathrm{RMS}}$, with a peak value of about $4 \mathrm{~A}$, as can be seen in Figure 7. It is important to note that the inverter output current is measured as positive in case it flows away from the inverter. The grid currents show some distortion. In order to reduce this distortion, some changes must be made to the low-level gridcoupled inverter control scheme. This topic has not yet been tackled and wil probably receive more attention during the following stages of the VSYNC project.

The third test illustrates simultaneous control of the DC link voltage, the reactive power exchange with the grid and DC-DC converter current. The results of this test are depicted in Figure 8 . The upper graph shows grid-coupled inverter output currents (with the reactive current magnitude reference in black), the middle graph depicts the grid voltage and the DC link voltage
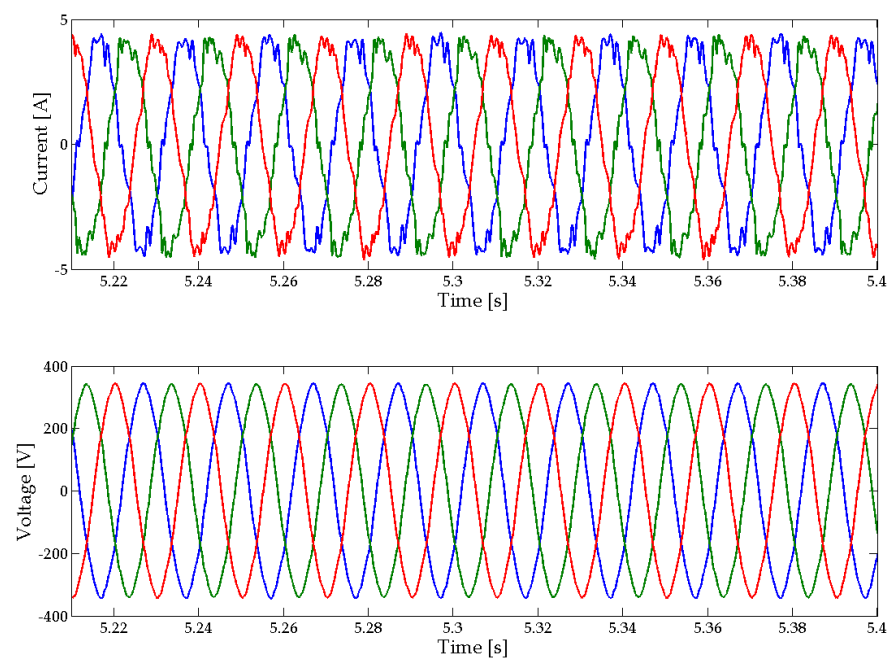

Fig. 7. Detailed view of the grid-coupled inverter output current and the grid voltage during the second experiment

is shown in the lower graph. At first, the DC-DC converter delivers $1 \mathrm{~kW}$ to the inverter DC link (corresponding to a current of 10 A with a generator voltage of $100 \mathrm{~V}$ ) and the reactive power exchange with the grid is controlled to be 0 kVAR. As expected the DC link voltage lies slightly above its reference and the inverter output current contains some distortion. At $t=4 \mathrm{~s}$, the reactive current magnitude reference is increased to $10 \mathrm{~A}$, corresponding to a reactive power exchange of 4,88 kVAR between the inverter and the grid. It can be seen that the current control succeeds in reaching the desired output current very fast. The DC link voltage drops slightly, decreasing the deviation from the reference value.

\section{Conclusion}

This paper describes the layout and performance of the rapid prototyping inverter platform used for the VSYNC project. The main goal of this project is to show that power electronic
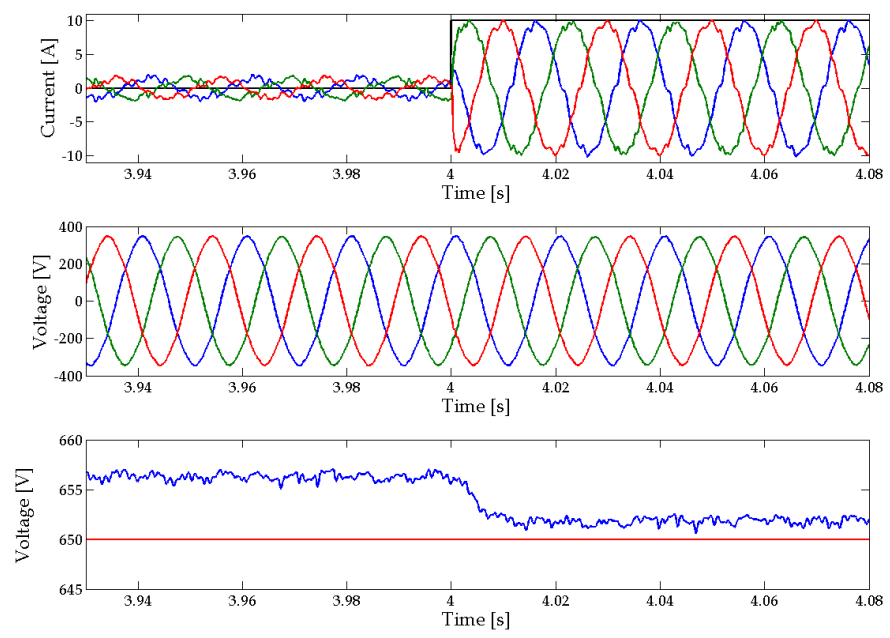

Fig. 8. Simultaneous control of the DC link voltage, the reactive power exchange with the grid and the DC-DC converter current 
converters, equipped with some energy storage unit(s) and controlled to emulate a virtual rotational inertia, are able to stabilize the grid frequency in case of mismatches between the power demand and generation in the (micro)grid. These converters are called Virtual Synchronous Generators (VSGs). First the layout and operation of the inverter platform, consisting of two inverters with a common DC link as well as the necessary filter passives, measurements and contactors, is described. The platform allows the user to design a Matlab Simulink control model, upload it to the Target PC and connect the Engineering PC to the Target PC to allow realtime control of and interaction with the inverter cabinet. Next the VSG control scheme is discussed. This can be divided into three parts: high-level control of the grid-coupled inverter, involving emulation of rotational inertia and providing active and reactive power references to be exchanged between the inverter and the grid; low-level control of the grid-coupled inverter, controlling the power exchange between the inverter and the grid; and finally the control of the DC-DC converters, interfacing DC energy storage units, generators and/or loads to the inverter DC link. The performance of the hardware and control components described earlier is then illustrated using the results of three tests, involving control of he inverter DC link voltage, reactive power exchange with the grid and control of the DC-DC converter current exchange with the inverter DC link. As a conclusion, it can be stated that the hardware and control schemes allow the project partners to perform laboratory tests using various types of high-level control. After the final control scheme has been decided upon, the performance of the VSG in a real low-voltage grid will be examined during the field tests.

\section{ACKNOWLEDGMENT}

The authors would like to thank the European Commission for the financial support (VSYNC Project, FP6 framework, contract no. FP6-038584).

\section{REFERENCES}

[1] http://www.vsync.eu

[2] K. Visscher and S. W. H. de Haan, Virtual Synchronous Machines (VSG's) for Frequency Stabilisation in Future Grids with a Significant Share of Decentralized Generation, CIRED Seminar 2008: SmartGrids for Distribution, Frankfurt, Germany, June 23-24, 2008

[3] http://www.triphase.com

[4] J. Van den Keybus and J. Driesen, Performance of Real-Time Power Electronic Converter Control Algorithms Implemented on a Personal Computer, Proceedings of the 2006 IEEE International Symposium on Industrial Electronics (ISIE), Vol. 4, July 9th-13th, 2006, pp. 3281 - 3286.

[5] J. Van den Keybus, Development of a Universal Electric Energy Measurement and Control Platform for Low-Voltage Grid-Coupled Applications in a Deregulated Electricity Market, $\mathrm{PhD}$ dissertation, KU Leuven, Belgium, December 2003.

[6] K. De Brabandere, B. Bolsens, J. Van den Keybus, A. Woyte, J. Driesen and R. Belmans, A Voltage and Frequency Droop Control Method for Parallel Inverters, IEEE Transactions on Power Electronics, Vol. 22, No. 4, July 2007, pp. 1107-1115.

[7] J. Morren, S. W. H. de Haan and J. A. Ferreira, Contribution of DG Units to Primary Frequency Control, European Transactions on Electrical Power, Vol. 16, Issue 5, September 2006, pp. 507-521.

[8] B. Bolsens, K. De Brabandere, J. Van den Keybus, J. Driesen and R. Belmans, Model-Based Generation of Low Distortion Currents in GridCoupled PWM-Inverters Using an LCL Output Filter, IEEE Transactions on Power Electronics, Vol. 21, No. 4, July 2006, pp. 1032-1040.
[9] B. Bolsens, K. De Brabandere, J. Van den Keybus, J. Driesen and R. Belmans, Three-Phase Observer-Based Low Distortion Grid Current Controller Using an LCL Output Filter, Proceedings of the 36th IEEE Power Electronics Specialists Conference (PESC), Recife, Brazil, June 12-16, 2005, 7 pages.

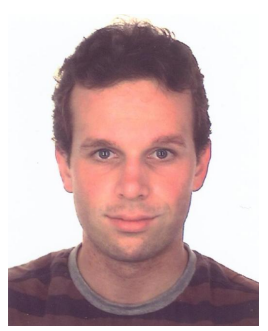

Tom Loix was born in 1982 in Leuven, Belgium. $\mathrm{He}$ received the M.Sc. degree in Electrical Engineer from the K.U. Leuven, Belgium, in 2005. He is currently pursuing a Ph.D. degree in Electrical Engineering at the ELECTA research group from the K.U. Leuven. His main research interests are the control of grid-connected inverters, microgrids, uninterruptible power supplies and inverter output filter design.

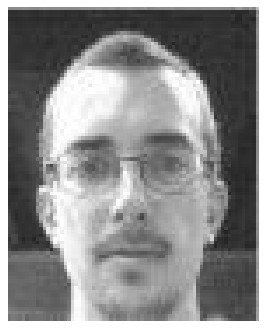

grid quality. Sven De Breucker was born in 1980 in Belgium.
He received the M.Eng. degree in Electromechanics in 2002 from the De Nayer University College and the M.Sc. degree in Electrical Engineering in 2005 from the K.U. Leuven, Belgium and is currently pursuing a Ph.D. in Electrical Engineering at the Research Group ELECTA, K.U. Leuven. His main interests are power electronics and hybrid electric vehicles. His research focuses on the implementation of supercapacitors in distribution grids with a high penetration of intermittent energy sources to improve

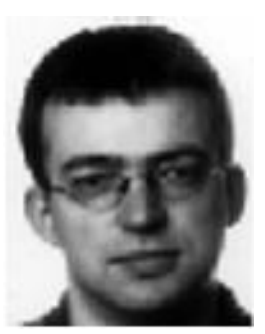

Piet Vanassche received the M.Sc. and Ph.D. degrees in Electrical Engineering from the K.U. Leuven, Belgium, in 1997 and 2003, respectively. His $\mathrm{Ph}$.D. research dealt with techniques for high-level exploration and tradeoff analysis for mixed-signal telecommunication systems. He currently works for Triphase, a K.U. Leuven spin-off specialised in power electronic rapid prototyping systems. Dr. Vanassche received a fellowship from the Institute for Science and Technology (IWT) for his Ph.D. research.

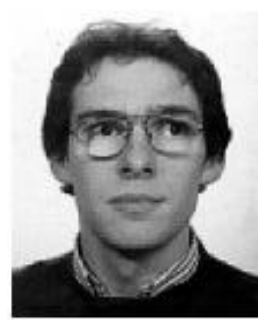

Jeroen Van den Keybus received the M.Sc. degree in Microelectronics and the Ph.D. degree in Electrical Engineering from the K.U. Leuven, Belgium, in 1998 and 2003, respectively. His Ph.D. dealt with power conversion applications in lowvoltage distribution grids in a deregulated market. $\mathrm{He}$ currently works for Triphase, a K.U. Leuven spinoff specialised in power electronic rapid prototyping systems, the origins of which lie in his Ph.D. work. 


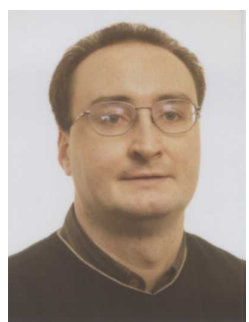

Johan Driesen was born in 1973 in Belgium. He received the M.S. degree in 1996 as Electrotechnical Engineer from the K.U. Leuven, Belgium. He received the $\mathrm{Ph} . \mathrm{D}$. degree in Electrical Engineering at K.U.Leuven in 2000 on the finite element solution of coupled thermal-electromagnetic problems and related applications in electrical machines and drives, microsystems and power quality issues. Currently he is an associate professor and teaches power electronics and drives at the KULeuven. In 2000-2001 he was a visiting researcher in the Imperial College of Science, Technology and Medicine, London, UK. In 2002 he was working at the University of California, Berkeley, USA. Currently he conducts research on distributed energy resources, including renewable energy systems, power electronics and its applications, for instance in drives, electrical transportation and power quality.

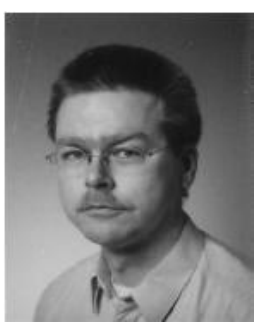

Klaas Visscher studied electrical engineering at a technical college before he went to university in 1982. He received his Master's degree in 1988 and his Doctor's degree in 1993, both in Applied Physics at Twente University in The Netherlands. Next he worked several years on automation projects in his own consultancy. In 1999 he joined the Energy Research Centre of The Netherlands, where he first worked on heat storage and thermal processes for renewable energy applications for three years. In 2003 he joined the Intelligent Energy Grids program of ECN, working in the field of distributed power generation. As research coordinator Grid Connection and Power Quality in the ECN Intelligent Energy Grids program, the main topics of his current research are control and stability of distributed electricity generation systems in future grids. 